\title{
Age trends in genotypic variation of wood density and its intra-ring components in young poplar hybrid crosses
}

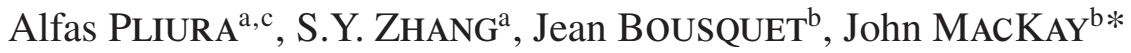 \\ ${ }^{a}$ Resource Assessment and Utilization Group, Forintek Canada Corp., 319 rue Franquet, Sainte-Foy, Québec, Canada G1P 4R4 \\ ${ }^{\mathrm{b}}$ Département des sciences du bois et de forêt et Centre de recherche en biologie forestière, Université Laval, Québec, Canada G1K 7P4 \\ ${ }^{\mathrm{c}}$ Current address: Department of Tree Genetics and Breeding, Lithuanian Forest Research Institute, Liepu 1, Girionys, Lithuania 53101
}

(Received 13 October 2005; accepted 30 March 2006)

\begin{abstract}
Age related dynamics of genotypic, phenotypic, and environmental variation, clonal repeatability, and genotypic correlations for wood density and its intra-ring components were analyzed in four poplar hybrid crosses, Populus deltoides $\times$ P. nigra, P. trichocarpa $\times$ P. deltoides, $P$. maximowiczii $\times$ P. balsamifera, and P. balsamifera $\times$ P. nigra, as well as $P$. deltoides. Using X-ray densitometry, measurements were taken on increment cores sampled in four clonal trials at 10 and 12 years of age from ramets of 19 clones. Wood density of all hybrid crosses was highest at the pith and decreased with increasing cambial age. The significance of the hybrid cross effect increased with age for mean wood density, dry fiber weight, and ring width. The coefficient of genotypic variation of cumulated mean wood density was rather stable over the 10-year period at all three sites, and ranged from $4.8-6.8 \%$. Clonal repeatability increased with age from 0.46 to 0.79 , mainly because of decreasing random variation. Corresponding genotypic parameters for individual rings varied greatly with age and across sites. Significance of the site effect on wood density tended to decrease with age. Significant negative genotypic correlations between ring width and wood density were found at only two of the four sites and they weakened with age. Age-age genotypic correlations between wood densities at ages 10 and younger were strong and significant from age 6 and over. This trend suggests that selection before this age would be unreliable.
\end{abstract}

poplar hybrids / clones / wood density / radial growth / age trend / genotypic variation / repeatability / genotypic correlation

Résumé - Variabilité génotypique inter-annuelle de la densité du bois et de ses composantes intra-cerne chez de jeunes peupliers hybrides. La dynamique inter-annuelle de la variabilité génotypique, phénotypique et environnementale, de la répétabilité clonale et des corrélations génotypiques entre paramètres de densité du bois ont été analysées pour quatre hybrides de peuplier: Populus deltoides $\times$ P. nigra, P. trichocarpa $\times$ P. deltoides, P. maximowiczii $\times$ P. balsamifera, and $P$. balsamifera $\times P$. nigra, ainsi que pour $P$. deltoides. Les mesures ont été effectuées par microdensitométrie à rayon X sur des carottes échantillonnées à partir des ramets de 19 clones issus de quatre tests clonaux (âge : 10 et 12 ans). Les résultats montrent que la densité du bois de tous les hybrides est la plus élevée près de la moëlle puis qu'elle diminue avec l'âge cambial. L'effet statistique du type d'hybrides augmente avec l'âge pour la densité moyenne, le poids sec des fibres et la largeur de cernes. Les coefficients de variation génotypique pour la densité moyenne du bois sont stables au cours des 10 ans sur 3 sites et s'élèvent à 4.8-6.8\%. La répétabilité clonale augmente avec l'âge de 0.46 à 0.79 . Les paramètres génotypiques pour les caractéristiques individuelles des cernes varient fortement avec l'âge et les sites. Le degré de signification de l'effet site tend à décroître avec l'âge pour la densité du bois. Des liaisons négatives significatives entre largeur de cernes et densité du bois sont observées sur seulement 2 des 4 sites et leur intensité s'affaiblit avec l'âge. Les liaisons génotypiques entre densité du bois à 10 ans et à des âges plus jeunes sont fortes et significatives à partir de 6 ans et au-delà. Une sélection avant cette âge semble donc peu fiable.

peuplier / hybride / clone / densité du bois / croissance radiale / génotype

\section{INTRODUCTION}

Wood density is considered to be the most important wood property in relation to other properties of the wood and has a major impact on the commercial value of both fibrous and solid wood products [52]. Studies on inter-clonal and intraclonal variation of wood density in poplar species $[10,13,22$, $33,35,39]$ or on individual poplar hybrids [16, 26,31,47] have shown the presence of significant genotypic (clonal) variation within hybrids in physical and mechanical properties. These findings indicate that breeding for genetic improvement of wood density and related wood properties is possible. How-

\footnotetext{
*Corresponding author: tony.zhang@qc.forintek.ca
}

ever, results obtained using the same species or hybrid vary depending on the age of the material. Some studies on efficiency of selection often assume that genetic variation and heritability remains constant with age [e.g. 7,14$]$ and possible changes in these genetic parameters are not considered in choosing an optimal time for evaluation and selection or in defining the length of breeding cycles. However, numerous studies have shown that genetic parameters (genetic variation, heritability, genetic correlations) of wood properties and other traits change with age $[6,17,20,23,28,46]$. These changes may have a significant influence on genetic gains and correlated genetic responses. Therefore a lot of emphasis was given to developing early testing methodologies. Despite numerous reports on wood density 
Table I. Main characteristics of hybrid poplar clonal trials.

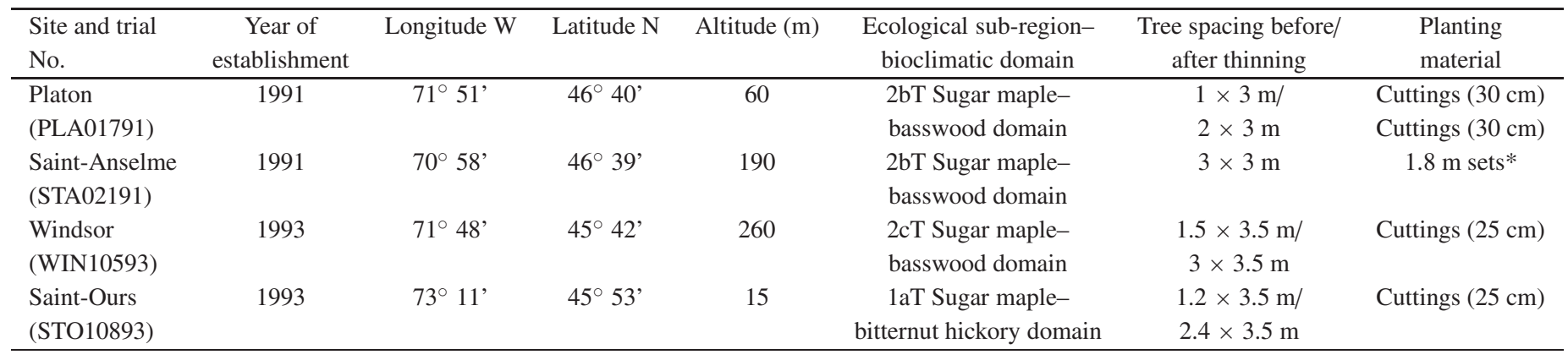

* Unrooted stock composed of 2-year-old stem material and planted $50 \mathrm{~cm}$-deep.

changes within trees from bark to pith and on genotypic variation of wood properties in poplar hybrids at different ages, there is very limited information on changes of genotypic variation, heritability, and genotypic correlations of wood density with age or with distance from pith to bark. Some preliminary indications are given only by Riemenschneider et al. [41]. Early selection based on use of young progenies for predicting mature wood density requires knowledge of juvenile-mature wood density relationships. It is widely known that environmental factors and silvicultural practices influence physical and mechanical properties of wood [53]. Yet, no studies on age-related dynamics of poplar wood property-associated genetic parameters have been conducted on the same material at different sites. Such information is crucial to choosing the most appropriate time for selection and achieving the highest possible genetic gains.

Wood density is a composite trait of several intra-ring components, including minimum and maximum wood densities, early- and latewood densities, proportion of early to latewood, etc. The influence of each parameter on mean wood density of a ring varies in a correlated fashion with other parameters or independently, and a particular value of mean wood density can result from various combinations of its components. Therefore, knowledge of genetic variation, level of genetic control, and genetic correlations among these components will contribute to a better understanding of the genetic control of wood density. This information can also be useful for improving the efficiency of tree breeding by using as substitute for wood density other wood density components that are most heritable and genetically variable, and less negatively correlated with growth traits. Knowledge of the dynamics of genetic parameters of wood density components and their dependence upon site conditions is also needed to include wood density as one of the selection criteria in eco-regionally based poplar breeding programs.

The objectives of this study were to: (1) estimate age trends in among-hybrid and among-clone (genotypic) variation and repeatability of wood density and its intra-ring components at different sites, (2) examine the age trends in relationships among wood density components, and (3) explore the implications of age- and site-related changes of genetic parameters for the efficiency of poplar breeding programs.

\section{MATERIALS AND METHODS}

\subsection{Materials}

This study was based on material collected from four clonal trials of poplar hybrids established by the Forest Research Branch of the Quebec Ministry of Natural Resources in southern Québec, Canada (Tab. I). The sites represent major soil types in which hybrid poplar clones are expected to be planted in southern Québec. All sites were originally abandoned agricultural land. Each clonal trial was established in a randomized complete block design, with ten blocks each. Clones were planted in row plots, each containing four trees. One systematic thinning was carried out (by removing every second tree in a row) in 1995 at the Platon site and in 1996 at the Windsor and Saint-Ours sites.

A subset of three hybrid crosses, Populus deltoides Bartr. ex Marsh $\times$ P. nigra L., P. trichocarpa Torr. \& Gray. $\times$ P. deltoides, $P$. balsamifera L. $\times P$. nigra and $P$. deltoides had been selected for this study at each clonal trial. The forth hybrid P. maximowiczii Henry $\times$ $P$. balsamifera was available for sampling at the Windsor and SaintOurs trials only. Four clones for each of $P$. deltoides $\times P$. nigra, $P$. balsamifera $\times$ P. nigra, $P$. maximowiczii $\times P$. balsamifera and of $P$. deltoides and three clones of $P$. trichocarpa $\times P$. deltoides were sampled. Clone No. 3226 of $P$. trichocarpa $\times P$. deltoides hybrid was not present at the Saint-Anselme site. Information on identity and origin of clonal material is presented in [37]. The selection of hybrids for this study was based on available information on growth rate and some adaptive traits including cold hardiness and insect and disease resistance. However, as most of these traits were not correlated with wood density and no information were available a priori on the wood characteristics of the parents or the progenies, the total sample of clones in terms of wood density can be considered as random. In the beginning of December 2002, four trees per clone were randomly sampled in each site, one ramet of each clone per randomly selected block, totaling 278 trees.

\subsection{Measurements}

To assess wood density components, a $12 \mathrm{~mm}$ diameter bark-topith core of wood was taken at a height of $1.3 \mathrm{~m}$ using an increment borer. Cores were taken at the same direction in every tree at all sites. Each increment core was put into a plastic bag and kept frozen until it was needed for X-ray densitometry. All cores were sawn into 1.57 
$\mathrm{mm}$ thick strips with a specially designed pneumatic-carriage twinbladed saw. Strips were then air-dried under restraint to prevent warping. Wood density component measurements of individual growth rings, minimum and maximum wood density, and ring width were obtained from microdensitometer profiles obtained using a direct reading X-ray densitometer at Forintek Canada Corp. A description of $\mathrm{X}$-ray densitometry analysis can be found in Zhang and Morgenstern [48] and Koga and Zhang [25]. Age trends in changes and variation of mean wood density and its components, minimum and maximum densities, ring width, and composite trait dry fiber weight were examined in two ways: (1) as individual annual rings from 3 to 10 years of cambium age and (2) as means of cumulated rings for the 8 periods starting from the 3-year-age period to the 10-year-age period. For the trees from the Platon and Saint-Anselme sites, wood density components of rings 11 and 12 were not used in analyses as trees at these sites were two years older than those at the Windsor and SaintOurs sites. Values for cumulated rings are equivalent to mean values for the tree at different ages. Area-weighted wood density for cumulated rings was calculated based on average density of each ring and ring area, and allowed for an estimate of average wood density of the whole disk of a tree trunk. Dry fiber weight for each ring was calculated by multiplying an average ring density and the ring volume.

\subsection{Statistical analysis}

Mixed model equations (MME) and the restricted maximum likelihood (REML) method were used in analysis of variance to estimate the significance of effects of different factors and to compute variance components. Variance analysis was done using the MIXED procedure in the SAS ${ }^{\circledR}$ Software [42]. The $Z$ test was carried out to test where random effects were significantly different from zero. The significance of fixed effects was tested with the $F$ test.

Wood density of each ring was considered as a separate trait and its analysis was done individually on among-tree variation basis, thus separating from within-tree variation sources. The following mixed linear models were used for joint analyses of the four sites together and for separate analyses of individual sites: joint:

$$
y_{i j k l}=\mu+s_{j}+h_{k}+c_{i(k)}+c_{i(k)} s_{j}+h_{k} s_{j}+e_{i j k l,}
$$

separate:

$$
y_{i k l}=\mu+h_{k}+c_{i(k)}+e_{i k l}
$$

where $y_{i j k l}$ is an observation on the $l$ th ramet from the $i$ th clone in the $k$ th hybrid cross in the $j$ th site, $y_{i k l}$ is an observation on the $l$ th ramet from the $i$ th clone in the $k$ th hybrid cross, $\mu$ is the overall mean, $s_{j}$ is the fixed effect due to the $j$ th site, $h_{k}$ is the fixed effect due to the $k$ th hybrid cross, $c_{i(k)}$ is the random effect due to the $i$ th clone in the $k$ th hybrid cross, $h_{k} . s_{j}$ is the fixed effect of interaction between the $k$ th hybrid cross and $j$ th site, $c_{i(k)} . s_{j}$ is the random effect of interaction between the $i$ th clone in the $k$ th hybrid cross and $j$ th site, $e_{i j k l}$ and $e_{i k l}$ are the random residuals. The models assume that the random effects are normally distributed with expectation zero and corresponding variances, $\sigma_{c(h)}^{2}, \sigma_{c(h) s}^{2}$, and $\sigma_{e}^{2}$. It was assumed that total clonal variance within all hybrids pooled describes the genotypic variance in the experiment, $\sigma_{c(h)}^{2}=\sigma_{G}^{2}$.

Assumptions of normal distribution of residuals and variance homogeneity for each trait were tested by using the GLM and UNIVARIATE procedures in $\mathrm{SAS}^{\circledR}$ [42]. Dry fiber weight was square root transformed to obtain a normal distribution of residuals and homogeneity of variances. Statistical significance of differences between least squared means of hybrids at each site was tested using the 'pdif' option of the SAS ${ }^{\circledR}$ MIXED procedure.

\subsection{Estimates of genetic parameters}

Variance components of random effects, genetic parameters, and their standard errors were derived separately for each site from a mixed model (2), using outputs from mixed model analysis of variance using the procedure MIXED of the SAS ${ }^{\circledR}$ software [42]. The effect of hybrid crossing was excluded from estimates of genotypic variances by including it in the ANOVA model as a fixed effect. The genotypic variance component expressed in percent of total phenotypic variation corresponds to the broad-sense-heritability.

The genotypic coefficient of variation was calculated using the following formula:

$$
C V_{G}=\sqrt{\sigma_{c}^{2}} \cdot 100 / \bar{X}
$$

where $\bar{X}$ is the phenotypic mean and $\sigma_{c}^{2}$ is the genotypic (clonal) variance component. Similarly, the environmental coefficient of variation was calculated from the residual variance. The coefficient of phenotypic variation was obtained from the phenotypic variance component, which was estimated as

$$
\sigma_{p h}^{2}=\sigma_{c}^{2}+\sigma_{e}^{2}
$$

where, $\sigma_{e}^{2}$ is the residual variance.

The repeatability of clonal means, which refers to genotypic heritability, was estimated as:

$$
R_{c}^{2}=\sigma_{c}^{2} /\left(\sigma_{c}^{2}+\sigma_{e}^{2} / k\right)
$$

where $\sigma_{c}^{2}$ is the genotypic (clonal) variance component, $\sigma_{e}^{2}$ is the residual variance and $k$ is the harmonic mean number of replications per clone. The standard errors for repeatability estimates were calculated following Swiger et al. [45] modified for unequal number of observations by Becker [1].

Genotypic correlation coefficients between traits at each site were estimated as [1]:

$$
r_{G}=\frac{\sigma_{c(x y)}}{\sqrt{\sigma_{c(x)}^{2} \times \sigma_{c(y)}^{2}}}
$$

where: $\sigma_{c(x y)}$ is the clone covariance component, $\sigma_{c(x)}^{2}$ is the clone variance component for the trait $x$ and $\sigma_{c(y)}^{2}$ is the clone variance component for the trait $y$. To estimate genotypic correlation coefficients, the data were standardized. Age-age genotypic correlations were estimated in the same way by substituting the covariance and variance components of traits $x$ and $y$ in the formula with corresponding components for the same trait measured at an early age and at a later age. Because of sampling errors and mathematical approximation, some genotypic correlations exceeded \pm 1 . In these cases, they were assumed to be equal to \pm 1 , considering the asymptotic nature of the distribution of correlation coefficients. The standard errors of genotypic correlations were computed using the equation by Falconer [9]. The rank correlations (Spearman) among clonal means at different pairs of sites were computed in order to estimate the relative importance of rank changes and scale effects in clone $\times$ site interaction. 
Table II. Results from joint mixed linear model (1) analysis of variance of wood density components for cumulated rings at 3, 6, and 10 yr old of hybrid poplar clones at four sites combined: means and standard errors, $F$-criteria and probability of fixed effects and variance components and standard errors for random effects as percent of the total random variation. Estimates for significant effects $(P<0.05)$ are indicated in bold.

\begin{tabular}{|c|c|c|c|c|c|c|c|c|c|c|c|}
\hline \multirow{5}{*}{ Trait } & \multirow{5}{*}{$\begin{array}{l}\text { Age } \\
(\mathrm{yr})\end{array}$} & \multirow{5}{*}{$\begin{array}{l}\text { Mean } \\
\pm \mathrm{se}\end{array}$} & \multicolumn{9}{|c|}{ Source of variation } \\
\hline & & & \multicolumn{6}{|c|}{ Fixed effects } & \multicolumn{3}{|c|}{ Random effects } \\
\hline & & & \multirow{2}{*}{\multicolumn{2}{|c|}{$\begin{array}{c}\text { Sites } \\
d f=3\end{array}$}} & \multirow{2}{*}{\multicolumn{2}{|c|}{$\begin{array}{l}\text { Hybrids } \\
\qquad d f=4\end{array}$}} & \multirow{2}{*}{\multicolumn{2}{|c|}{$\begin{array}{c}\text { Hybrids } \times \\
\text { Sites } \\
d f=10\end{array}$}} & \multirow{3}{*}{$\begin{array}{c}\begin{array}{c}\text { Clones within } \\
\text { hybrids }\end{array} \\
d f=13 \\
\sigma_{c(h)}^{2} \pm \mathrm{se} \\
(\%)\end{array}$} & \multirow{3}{*}{$\begin{array}{c}\text { Clones } \times \\
\text { Sites } \\
d f=32 \\
\sigma_{c(h) s}^{2} \pm \mathrm{se} \\
(\%)\end{array}$} & \multirow{3}{*}{$\begin{array}{c}\begin{array}{c}\text { Random } \\
\text { error }\end{array} \\
d f=207 \\
\sigma_{e}^{2} \pm \mathrm{se} \\
(\%)\end{array}$} \\
\hline & & & & & & & & & & & \\
\hline & & & $F$ & $P$ & $F$ & $P$ & $F$ & $P$ & & & \\
\hline \multirow{3}{*}{$\begin{array}{l}\text { Mean } \\
\text { density } \\
\left(\mathrm{kg} / \mathrm{m}^{3}\right)\end{array}$} & 3 & $362.4 \pm 3.9$ & 7.7 & $<0.001$ & 7.1 & 0.003 & 1.3 & 0.280 & $\mathbf{1 2 . 7} \pm 9.3$ & $8.1 \pm 10.0$ & $79.2 \pm 10.0$ \\
\hline & 6 & $358.6 \pm 2.5$ & 2.7 & 0.063 & 10.6 & $<0.001$ & 0.8 & 0.610 & $10.4 \pm 8.8$ & $21.3 \pm 9.7$ & $68.4 \pm 6.8$ \\
\hline & 10 & $344.9 \pm 2.2$ & 4.0 & 0.016 & 11.8 & $<0.001$ & 1.2 & 0.315 & $19.1 \pm 11.5$ & $16.0 \pm 8.5$ & $64.9 \pm 6.4$ \\
\hline \multirow{3}{*}{$\begin{array}{l}\text { Weighted } \\
\text { density } \\
\left(\mathrm{kg} / \mathrm{m}^{3}\right)\end{array}$} & 3 & $359.6 \pm 3.9$ & 8.0 & $<0.001$ & 8.2 & 0.002 & 1.1 & 0.376 & $11.9 \pm 9.1$ & $10.1 \pm 10.3$ & $78.0 \pm 9.8$ \\
\hline & 6 & $351.6 \pm 2.4$ & 4.3 & 0.012 & 11.9 & $<0.001$ & 1.2 & 0.333 & $11.5 \pm 8.7$ & $15.1 \pm 8.5$ & $73.4 \pm 7.3$ \\
\hline & 10 & $334.3 \pm 2.2$ & 6.4 & 0.002 & 12.3 & $<0.001$ & 1.6 & 0.142 & $22.6 \pm 12.3$ & $12.4 \pm 7.8$ & $65.0 \pm 6.5$ \\
\hline \multirow{3}{*}{$\begin{array}{l}\text { Minimum } \\
\text { density } \\
\left(\mathrm{kg} / \mathrm{m}^{3}\right)\end{array}$} & 3 & $278.4 \pm 3.5$ & 7.1 & $<0.001$ & 8.3 & 0.001 & 0.9 & 0.522 & $6.6 \pm 6.3$ & 0.0 . & $93.4 \pm 10.6$ \\
\hline & 6 & $263.5 \pm 2.4$ & 3.5 & 0.027 & 14.4 & $<0.001$ & 1.7 & 0.115 & $3.4 \pm 4.7$ & $7.6 \pm 7.9$ & $89.0 \pm 8.9$ \\
\hline & 10 & $250.0 \pm 2.1$ & 3.8 & 0.019 & 18.2 & $<0.001$ & 1.6 & 0.157 & $7.2 \pm 7.1$ & $17.4 \pm 9.9$ & $75.4 \pm 7.5$ \\
\hline \multirow{3}{*}{$\begin{array}{l}\text { Maximum } \\
\text { density } \\
\left(\mathrm{kg} / \mathrm{m}^{3}\right)\end{array}$} & 3 & $520.6 \pm 9.9$ & 2.6 & 0.069 & 5.2 & 0.010 & 1.1 & 0.421 & $1.3 \pm 4.2$ & 0.0 & $98.7 \pm 11.1$ \\
\hline & 6 & $517.6 \pm 5.2$ & 1.1 & 0.349 & 1.5 & 0.250 & 0.3 & 0.988 & $2.5 \pm 6.2$ & $21.3 \pm 10.2$ & $76.2 \pm 7.5$ \\
\hline & 10 & $505.8 \pm 3.7$ & 0.4 & 0.775 & 2.7 & 0.078 & 0.2 & 0.993 & $8.5 \pm 7.6$ & $13.8 \pm 8.4$ & $77.7 \pm 7.6$ \\
\hline \multirow{3}{*}{$\begin{array}{l}\text { Fiber dry } \\
\text { weight } \\
(\mathrm{kg})\end{array}$} & 3 & $2.0 \pm 0.2$ & 94.2 & $<0.001$ & 4.2 & 0.020 & 2.1 & 0.049 & $8.6 \pm 7.5$ & 0.0 . & $91.4 \pm 10.4$ \\
\hline & 6 & $13.5 \pm 0.7$ & 80.2 & $<0.001$ & 6.8 & 0.003 & 2.0 & 0.071 & $4.7 \pm 5.1$ & $1.4 \pm 6.6$ & $93.9 \pm 9.3$ \\
\hline & 10 & $45.8 \pm 1.7$ & 34.5 & $<0.001$ & 9.7 & 0.001 & 1.8 & 0.110 & $12.6 \pm 7.7$ & $2.9 \pm 6.4$ & $84.5 \pm 8.4$ \\
\hline Ring & 3 & $6.32 \pm 0.24$ & 51.2 & $<0.001$ & 3.3 & 0.046 & 1.2 & 0.313 & $10.4 \pm 8.4$ & $3.6 \pm 9.0$ & $86.0 \pm 10.7$ \\
\hline width & 6 & $7.92 \pm 0.16$ & 16.6 & $<0.001$ & 7.3 & 0.003 & 0.7 & 0.740 & $2.8 \pm 4.7$ & $12.6 \pm 8.4$ & $84.6 \pm 8.4$ \\
\hline$(\mathrm{mm})$ & 10 & $7.97 \pm 0.13$ & 7.9 & $<0.001$ & 11.2 & $<0.001$ & 0.9 & 0.520 & $9.9 \pm 7.3$ & $13.8 \pm 8.4$ & $76.3 \pm 7.6$ \\
\hline
\end{tabular}

\section{RESULTS}

\subsection{Changes in variation among sites with age}

The joint ANOVA (model 1) shows that site effects were statistically significant at most ages for all traits except for maximum wood density (Tab. II). Significance of the site effect on dry fiber weight was much higher than it was on wood density components. However, it tended to decrease with age. For wood density traits, the significance of the site effect was much smaller than the hybrid effect while it was higher on dry fiber weight (Tab. II). Trees at the Saint-Anselme site had the highest mean wood density at a young age. However, it decreased considerably during the following seven years. Site means for individual rings decreased from 392.2 to $316.6 \mathrm{~kg} / \mathrm{m}^{3}$ and for cumulated rings, it decreased from 397.5 to $351 \mathrm{~kg} / \mathrm{m}^{3}$ (Fig. 1). At more productive sites (Windsor and Saint-Ours), the decrease in wood density was not severe. The minimum wood density showed a clear decrease with age at less productive sites (Platon and Saint-Anselme) (from 288.3 to $247.4 \mathrm{~kg} / \mathrm{m}^{3}$ and from 308.0 to $259.9 \mathrm{~kg} / \mathrm{m}^{3}$, respectively). However, this decrease was less pronounced at other sites. On the other hand, maximum wood density was more stable and decreased with age at the Saint-Anselme site only (from 577.1 to $504.6 \mathrm{~kg} / \mathrm{m}^{3}$ ). The wood density components showed no signs of increase by the end of the 10 -year-old period at any site. The radial growth (cumulated ring width) of poplar hybrids was initially fastest at the Saint-Ours site. However, it decreased steadily over 10 years of cambium age while at all other sites, the radial growth increased slightly (data not shown).

\subsection{Age trends in variation among hybrids}

A significant effect $(P<0.003)$ by hybrid cross was shown by the joint ANOVA for variation of mean and minimum wood densities of cumulated and individual rings and for weighted wood density of cumulated rings starting from 3 years of age, and its significance showed a steady increase with age (Tab. II). The hybrid effect was less significant for fiber weight and ring width.

The coefficient of variation of hybrid means $\left(C V_{H}\right)$ for wood mean density of individual rings varied substantially from year to year while $\mathrm{CV}_{H}$ for mean wood density of cumulated rings was stable at $10-11 \%$ (Fig. 2). The coefficient 

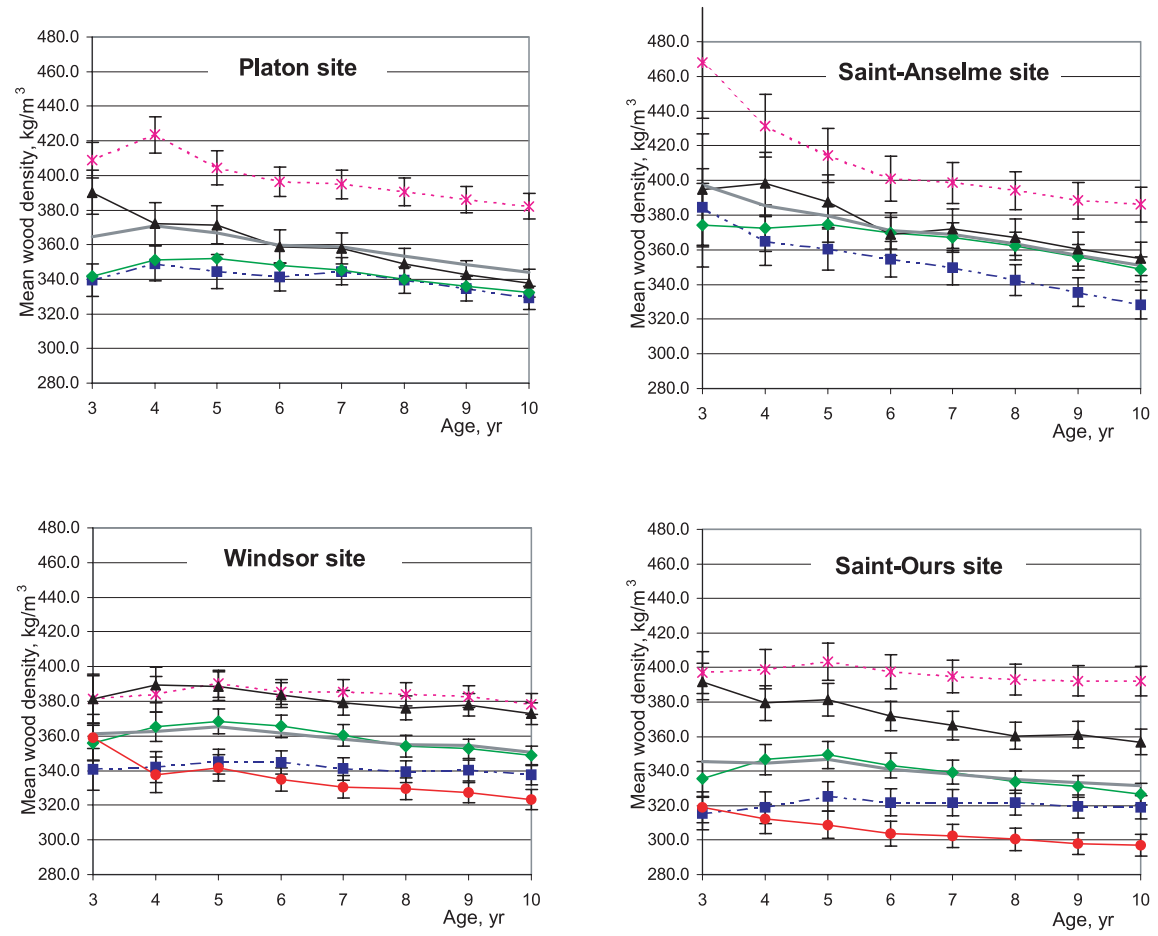

Figure 1. Changes in mean wood density of cumulated rings with age for different poplar hybrid crosses and $P$. deltoides at four sites. Error bars indicate standard errors of hybrid means. Mean of a site $-*-P$. deltoides, $\longrightarrow$ $P$. deltoides $\times$ P. nigra,$\longrightarrow$ P. trichocarpa $\times$ $P$. deltoides,$\longrightarrow P$. maximowiczii $\times$ P. balsamifera, and -- balsamifera $\times$ P. nigra. of variation of hybrid means $\left(C V_{H}\right)$ for wood mean density was higher than coefficients of genotypic variation $\left(C V_{G}\right)$ at all sites and ages except for the Saint-Anselme site.

The wood density of cumulated rings of individual hybrids changed with age by $4.3-92.0 \mathrm{~kg} / \mathrm{m}^{3}$ and with site by $1.1-28.8 \mathrm{~kg} / \mathrm{m}^{3}$ (at 10 years of age). Some hybrids slightly changed their ranks during the period of 3 to 4 years of age. Afterwards, however, the age trend lines of all hybrids became almost parallel (Fig. 1). At the least productive site of Platon, the differences in mean wood density among all hybrids were not significant and only $P$. deltoides had a significantly higher wood density during the $3-10$-year period. The $P$. trichocarpa $\times P$. deltoides hybrid cross had a significantly higher wood density of cumulated rings than other hybrids at more productive sites of Windsor and Saint-Ours. However, at almost all ages, it was still lower than that of $P$. deltoides, which had the highest wood density at almost all sites, varying with age and site from 371.3 to $467.7 \mathrm{~kg} / \mathrm{m}^{3}$ (Fig. 1). The P. maximowiczii $\times$ P. balsamifera hybrid cross had the lowest mean density of individual rings $\left(277.6-348.7 \mathrm{~kg} / \mathrm{m}^{3}\right)$ in most years. The $P$. balsamifera $\times P$. nigra hybrid cross also had a low mean wood density at all sites and for most ages.

For minimum wood density, the among-hybrid variation slightly increased with age at all sites and it had a level of variation similar to that of mean wood density (Fig. 2). The among-hybrid variation in maximum density was much lower than that in minimum density and it decreased with age at all sites (Fig. 2).

$C V_{H}$ for the width of cumulated rings were about twice as high as those for wood density. The changes with age showed different patterns at each site. $C V_{H}$ steadily increased at the Platon site, whereas it decreased until 5 to 6 years of age and then stabilized or started to increase again at the three other sites. $P$. deltoides and most of the hybrids had their ranks changed for ring width with age (data not shown). Only the $P$. trichocarpa $\times P$. deltoides hybrid cross had significantly larger individual ring width than other hybrids or $P$. deltoides at all sites and years. The radial growth of trees from the P. balsamifera $\times$ P. nigra hybrid cross was the slowest at the SaintAnselme and Saint-Ours sites. At the Platon and Windsor sites, the lowest growth was observed for trees of $P$. deltoides. The cumulated ring width of trees of $P$. deltoides increased at all sites up to 4 to 6 years of age, followed by a decrease. On the other hand, for all hybrids, it increased up to 9 years of age at most sites except the Saint-Ours site (data not shown).

Similar age trends to the ones observed for ring width were found for the among-hybrid variation in dry fiber weight (Fig. 2). The $P$. trichocarpa $\times P$. deltoides hybrid cross had a significantly larger fiber dry weight of cumulated rings than did the other hybrids or P. deltoides at all sites, and these differences increased steadily with age (data not shown). The fiber dry weight of the $P$. deltoides $\times P$. nigra hybrid exceeded significantly the site means at the Platon and Windsor sites starting from 7 years of age.

The hybrid $\times$ site interaction was statistically significant (0.01 $<P<0.05)$ only for dry fiber weight of cumulated rings at $3,4,5$, and 8 years of age while at other ages, it was close to significance (Tab. II).

\subsection{Age trends in clonal variation and repeatability}

The ANOVA for joint analysis of sites (model 1) indicated statistically significant $(0.01<P<0.05)$ clonal effects within 

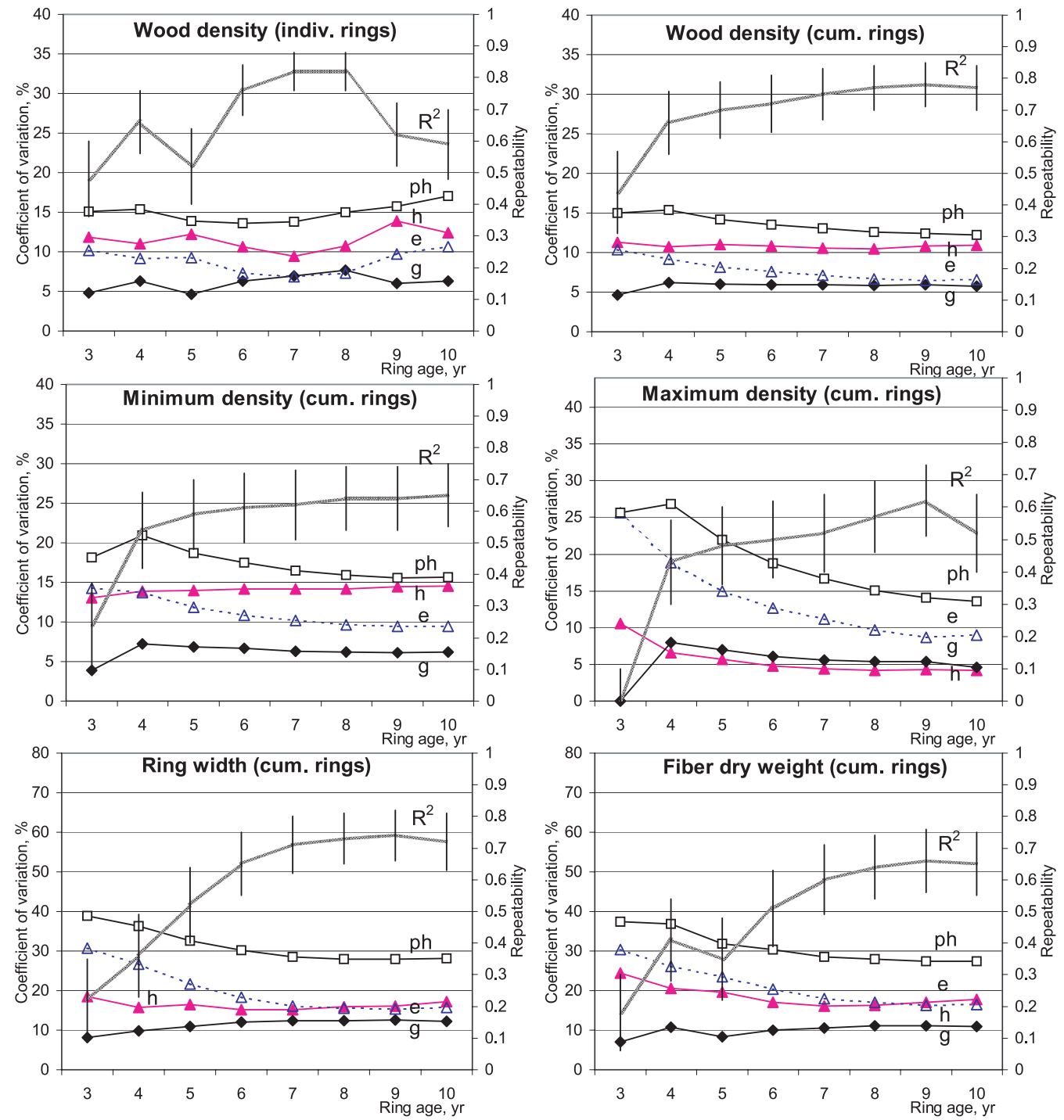

Figure 2. Changes with age in phenotypic (ph), among-hybrid (h), genotypic (among clones within hybrids) (g), and environmental coefficients of variation (e), and clonal repeatability ( \pm standard errors) of mean wood density of individual and cumulated rings, minimum and maximum wood densities, ring width, and dry fiber weight of cumulated rings of poplar hybrids at the Saint-Ours site.

hybrids for weighted and mean wood densities of cumulated rings at most ages as well as for dry fiber weight and ring width at 10 years of age (Tab. II). However, clonal variance components were not high.

For individual sites (model 2 of ANOVA), significant clonal effects $(0.01<P<0.05)$ were obtained for mean wood density of cumulated rings at all sites (except the Platon site) starting primarily from 4 to 5 years of age, with corresponding clonal variance components varying from 34.5 to $39.9 \%$ at the Saint-Anselme site, from 34.1 to $43.8 \%$ at the Windsor site, and from 31.3 to $43.4 \%$ at the Saint-Ours site. However, $C V_{G}$ was rather low, with values from 5.7 to $7.1 \%$ (Fig. 2). $C V_{G}$ was stable over all years at the Saint-Ours and Windsor sites. On the other hand, it showed a tendency to decrease with age at the Saint-Anselme site while it increased at the Platon site. For mean wood density of individual rings, slightly smaller but statistically significant clonal effects were found, with lower clonal variance components at 3 to 5 and 9 to 10 years of age (data not shown). The annual variation of $C V_{G}$ for mean wood density of individual rings was more pronounced than for cumulated rings.

The clonal repeatability of mean wood density of individual rings differed across sites and varied greatly year-by-year, reaching the highest levels at different ages at different sites $(0.44 \pm 0.14$ and $0.76 \pm 0.09$ at 9 years of age at the Platon and Saint-Anselme sites, respectively, and $0.72 \pm 0.09$ and $0.82 \pm 0.06$ at 7 years of age at the Windsor and Saint-Ours sites, respectively). Clonal repeatability estimates for cumulated rings steadily increased with age at all sites, from values of 0.46 to 0.79 with stabilization at their highest levels starting from 5 to 10 years of age at most of the sites. At the Platon site, this increase started later than at other sites. The broad-sense 
individual heritability substantially increased with age from $0.17 \pm 0.12$ to $0.43 \pm 0.12$ and from $0.24 \pm 0.16$ to $0.44 \pm 0.12$ at the Saint-Ours and Windsor sites, respectively, while at the Platon and Saint-Anselme sites, it showed almost no increase (from 0 to $0.13 \pm 0.13$ and from $0.35 \pm 0.12$ to $0.40 \pm 0.16$, respectively). A steady decrease of phenotypic and residual variation with age was observed for mean and weighted wood densities of cumulated rings (Fig. 2) while for individual rings, it varied year-by-year substantially, with a slight increase at 10 years of age (data not shown).

Statistically significant $(0.01<P<0.05)$ clonal effects on minimum wood density of cumulated rings were found at the Saint-Anselme and Saint-Ours sites, starting from 9 and 5 years of age, respectively (data not shown). For maximum wood density, the clonal effects were statistically significant at the Platon, Saint-Ours, and Windsor sites from 8, 6, and 6 years of age, respectively. Repeatability estimates of both wood density components were slightly lower than those for mean wood density. However, repeatability steadily increased with age, except for maximum density at the end of the 10year period (Fig. 2). $C V_{G}$ for minimum wood density was at a rather stable low level, with values of 4.6 to $9.0 \%$, while for maximum wood density, it was higher (from 5.1 to $15.0 \%$ ). However, it steadily decreased, down to 4.9 to $5.3 \%$, by 10 years of age. The phenotypic and environmental variations of minimum wood density showed a slightly decreasing trend with age, while for maximum wood density they decreased considerably at all sites (Fig. 2).

Statistically significant clonal effects on variation of cumulated rings width were observed only at the Saint-Anselme and Saint-Ours sites, starting from 6 and 7 years of age, respectively. The clonal variance component (data not shown) was of a similar level to that for wood density traits. However, $C V_{G}$ was two to three times higher (Fig. 2), with high repeatability estimates starting from 6 years of age.

For dry fiber weight, a slight increase of clonal variation starting at 6 to 8 years of age as well as a steady decrease of environmental variation was observed, thus resulting in an increase in clonal repeatability.

The clone $\times$ site interaction was significant $(P<0.05)$ for most cumulative traits studied starting 4 and 8 years of age, except for dry fiber weight (Tab. II). The interaction variance component for mean wood density reached its maximum at 6 and 7 years of age and was much larger than the clonal variance component.

\subsection{Changes in genotypic correlations between traits with age}

Genotypic correlations among pairs of traits at different ages at individual sites are presented in Figure 3. The genotypic correlations for mean and minimum wood densities at the Platon site and for ring width at the Windsor site were not estimated, as clonal effects were not significant. Significant $(P<0.05)$ negative genotypic correlations between mean wood density of cumulated rings and ring width showed a clear tendency to decrease with age from strong to moderate at the
Saint-Ours and Saint-Anselme sites (Fig. 3a). As indicated by strong negative genotypic correlations, minimum wood density also decreased with increasing ring width. However, the correlations weakened with age from about -1.0 at age 4 to -0.38 to -0.73 at age 10 (Fig. 3b). Genotypic correlations between maximum wood density and ring width were strong and negative at 4-5 years of age at the Platon, Saint-Anselme, and Saint-Ours sites. However, they steadily weakened to -0.40 or even became positive at age 10 (Fig. 3c). Genotypic correlations between mean and minimum wood densities of cumulated rings were close to 1 at all ages and sites (Fig. 3d). Strong positive genotypic correlations between mean and maximum wood densities slightly weakened, starting from 8-10 years of age (Fig. 3e). Genotypic correlations between maximum and minimum wood densities tended to gradually decrease with age from 1.0 to 0.85 at the Saint-Anselme, from 0.94 to 0.48 at Windsor, and from 1.0 to 0.63 at the Saint-Ours site. Strong negative genotypic correlations between mean wood density and dry fiber weight were found only at the Saint-Ours and Saint-Anselme sites, with a weakening trend with age being apparent at the Saint-Ours site (Fig. 3f). Genotypic correlations between ring width and dry fiber weight were always close to 1 at all sites and for all ages.

\subsection{Age-age genotypic correlations}

Age-age genotypic correlations for cumulated ring properties of poplar hybrids at 10 years of age with corresponding properties at ages starting from 4-6 years for most traits were close to 1.0. Correlations between wood density traits at age 10 and at 3-4 years of age were weaker, at 0.60 and 0.39 at the Saint-Anselme and Saint-Ours sites, respectively, while for the Platon and Windsor sites, correlations were not significant due to either the absence of a significant clonal effect or to large standard errors. Age-age genotypic correlations for dry fiber weight often exceeded 1.0.

\section{DISCUSSION}

\subsection{Changes in wood density and its variation with age}

Much smaller phenotypic variation in wood density was observed than in ring width, and its decrease with cambium age was smaller. This trend indicates that wood density is more stable than radial growth with regard to inter-tree variation as well as to variation related to cambium age within trees. Changes in inter-tree variation of wood density may be related to a gradual decrease of wood density with age, which was observed for all hybrid crosses at all sites. Previous studies on poplars and their hybrids have found wood density to be high near the pith, then dropping at mid-diameter and starting to increase outwards, as reported for $P$. alba L., $P$. grandidentata Michx., and $P$. tremuloides Michx. [24], P. tremuloides [4], P. trichocarpa [34], P. euramericana Dole. [16] and P. trichocarpa $\times P$. deltoides [8]. Thus, the decrease of wood density with age found in the present study may reflect the first stage of this pattern 
(a)

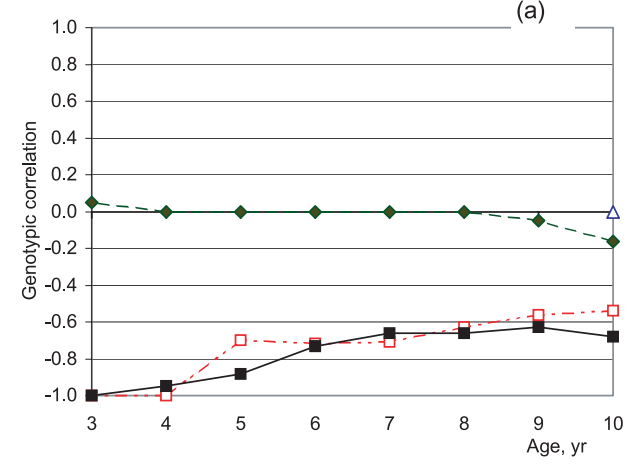

(c)
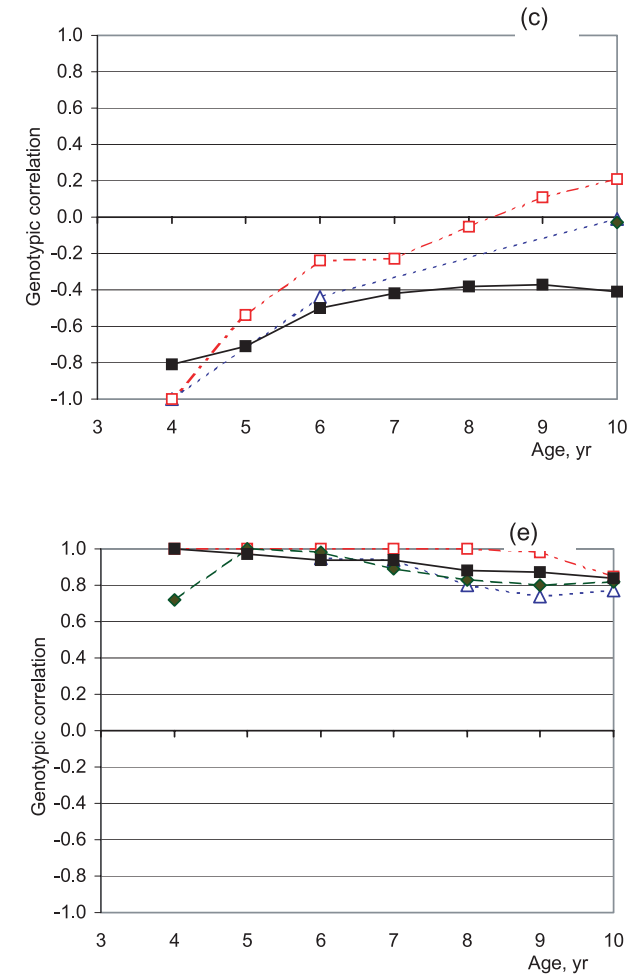

(b)
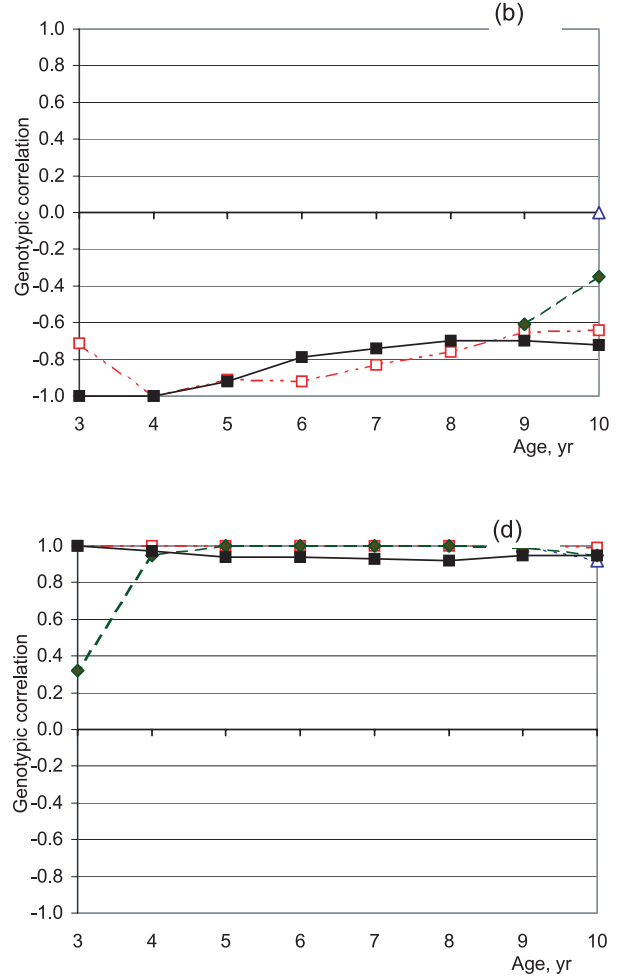

(f)

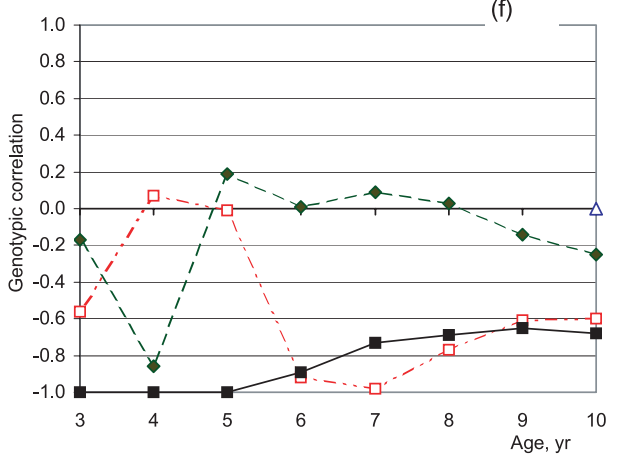

Figure 3. Age trends in genotypic correlations among cumulated ring properties of poplar hybrids: (a) ring width and mean wood density, (b) ring width and minimum wood density, (c) ring width and maximum wood density, (d) mean and minimum wood densities, (e) mean and maximum wood densities, (f) mean wood density and fiber weight for four sites: - -A- - Platon, $---\square---$ Saint-Anselme, - - - - Windsor, $\longrightarrow-$ Saint-Ours.

of change, as the hybrid poplars tested are still young and have not yet matured and achieved a corresponding increase in wood density. For instance, in $P$. deltoides, wood reaches maturity at about 17 to 18 years of age with a marked improvement of wood properties [2]. With age, the poplar hybrids tested here will presumably acquire increased wood density, thus resulting in an increase in radial variation within trees. This presumption must be verified in future studies.

The mean wood density of a ring is a composite of several intra-ring components, including wood density of early- and latewood and width of early- and latewood, that can vary together or independently. As it was not possible to precisely determine the width of late-wood in the rings of these poplar hybrids, we were able to analyze only the minimum and maximum wood densities that were specific to early-wood and latewood, respectively. This intra-ring variability is related to changing growth patterns within growing seasons, resulting in the formation of earlywood and latewood. In this study, the differences between minimum and maximum wood densities were much higher than differences due to cambium age, site or parentage, thus supporting the conclusions of Megraw [30] that the greatest variability in wood density occurs within each ring.

Zhang and Zhong [49] found that cambium age and ring width were able to explain a large part of the radial variation in wood density within trees and that the cambium age explains 
more variation than does the ring width (27.5 to $30.3 \%$ vs. 4.4 to $23.4 \%$; [50]).

\subsection{Changes in variation among sites with age}

Strongly significant site effects were observed on the growth traits of the hybrid poplars. These effects indicate that the test sites differ considerably in environmental conditions. Wood properties were affected by site possibly through different growth rate and development of trees at different sites as well as by heterogeneous competition effects. However, much lower $F$ values were obtained for the site effects related to wood density traits than for growth characters. Such a trend indicates that in general, wood properties were more stable than growth traits across environments. The decreasing significance of the site effect with age for all cumulated ring wood density components indicates that among-site stability for wood properties increases with age. This trend can result in a complete loss of the site effect at a more mature age. This possible outcome is already indicated by the loss of the site effect for wood density of individual rings at age 10 . The reduction of the site effect for the cumulated ring wood density with increasing age could also be related to the reduction of differences in sites through accumulation of varying effects of climatic years at different sites. The decrease in site effect might also be due to the competition at different sites becoming similar after thinning. Another reason could also be the increase of clone $\times$ site interaction observed in our study (Tab. II). These age related changes of the site effects on wood density traits might be the main reason why some studies have found statistically significant site effects for wood density in poplars or poplar hybrids $[32,51]$ while other studies have not $[18,29,40]$. The lack of a site effect in previous studies might also be related to a narrow range of wood density variation [29] or to small differences in environmental conditions of sites.

Our study also shows that site conditions differentially affect minimum and maximum wood densities. Statistically significant site effects were detected for minimum wood density but were absent for maximum wood density. Such a trend indicates that late wood properties are more stable across environments. Also, a highly significant site effect was found for dry fiber weight, that under the absence of $\mathrm{G} \times \mathrm{E}$ interactions indicates that poplar hybrids harbour a high phenotypic plasticity in dry biomass production. However, a decreasing significance of this site effect with age indicates that it tends to decrease as trees mature.

\subsection{Age trends in variation among hybrids}

Statistically significant hybrid effects were obtained by the joint ANOVA (model 1) for variation in wood densities starting from 3 years of cambium age. These effects indicate the existence of differences among hybrid crosses already at an early age. The comparison of variation trends at among-hybrid and random error levels shows that the significance of hybrid effects increased with age, mostly because of a decrease in the random error term, while the among-hybrid variation term remained stable. Similar decreases in environmental variance for wood density were found in studies of coniferous species $[17,20]$. It is noteworthy that the coefficient of among-hybrid variation did not change with age, even though wood density had decreased considerably. The coefficient of among-hybrid variation was higher than the coefficient of genotypic variation at almost all sites and ages. However, among-hybrid variation at less productive sites such as Platon and Saint-Anselme was largely due to the differences between the three hybrid crosses and $P$. deltoides, while differences among hybrid crosses were not significant at most ages.

In general, wood density of poplar hybrid crosses was lower than that of $P$. deltoides in the present study and than that reported elsewhere for stands of $P$. deltoides [38]. Lower wood density is generally considered to be a specific attribute of hybrid poplars, as compared to their native counterparts $[3,4]$. Substantial changes in the wood density of the different hybrid crosses included in this study were related to age and site, and these effects can explain differences in wood density for the same poplar hybrids in previous studies $[22,33]$. The present study demonstrated that intra-tree changes in wood density related to age were much larger than wood density changes over sites. Such an observation was also made by Larson [27], in that variation between rings within trees is larger than variation among trees growing on different sites.

Variation in dry fiber weight among hybrids was very high, although it showed a clear tendency to decrease with age at three of the four sites. Such a variation depends to a great extent on a large variation in stem volume. The dry fiber weights of $P$. trichocarpa $\times P$. deltoides and $P$. deltoides $\times P$. nigra hybrid crosses were the largest at all sites. Thus, these hybrid crosses can be considered as the best producers of dry fiber biomass at a variety of sites. Selection for high dry fiber weight was considered to be an optimal selection strategy that allows the achievement of a high genetic gain in dry fiber biomass while providing a good compromise between tree growth and wood quality $[48,51]$. The $P$. trichocarpa $\times P$. deltoides hybrid cross and $P$. deltoides can be qualified as having the highest phenotypic plasticity, as their dry fiber weights showed the highest increases with increasing site productivity. Part of the differences in phenotypic plasticity among hybrids resulted from a hybrid $\times$ site interaction. However, this interaction was rather small and decreased with age, thus indicating that differences among hybrids in site sensitivity as regards to dry biomass production are not high and tend to disappear with age.

\subsection{Age trends in clonal variation and repeatability}

Genotypic variation in wood density components changed with age. In addition, these patterns varied with site. $C V_{G}$ for mean wood density of cumulated rings was stable during all years at the Saint-Ours and Windsor sites. However, it decreased with age at Saint-Anselme and increased at the Platon site. Clonal effects in the joint ANOVA (model 1) were not highly significant $(0.01<P<0.05)$, possibly because of the 
presence of a clone $\times$ site interaction and the limited number of clones surveyed. Significant clonal genotypic variation in wood density of poplars and their hybrids at certain ages was also reported in previous studies $[4,22,26,36,47,51]$. However, this is the first study examining changes in genotypic variation of wood properties of poplar hybrids related to age. The results of the present study show that fluctuations in both genotypic and environmental variances have caused large fluctuations in clonal repeatability estimates for mean wood density of individual rings. However, for wood density of cumulated rings, the repeatability showed a steady increase starting from 3 to 5 years of age at most of the sites. The increase of repeatability was more due to a decrease in environmental variation (residuals) than due to changes in variation among clones (genotypic variation). Similar increases of heritability estimates with age were reported elsewhere for coniferous species and were due to a decrease of residual variance $[6,17,20]$. Changes in variances and thus in heritability estimates could be caused by changes in competition among trees in plantations due to thinning. Other possible reasons for the decrease in residual variance with age might be that more mature wood itself is likely less prone to environmental variation than juvenile wood.

The results of the present study show that none of the wood density components had repeatability estimates greater than those found for mean wood density at most ages and sites. Differing patterns of changes in heritability estimates and in genotypic variation with age and sites observed for maximum and minimum wood densities indicate that these features of early and latewood have different genetic backgrounds.

With regard to broad-sense individual heritability, the estimates for mean wood density were lower than those reported for $P$. deltoides $[10,13], P . \times$ euramericana hybrids and $P . n i$ gra [33], $P . \times$ euramericana hybrids [4], and $P$. balsamifera [22]. Lower estimates in the present study might have resulted from a lower number of clonal samples representing each hybrid cross, larger within-ring variation of wood density when measured by the X-ray technique, or because of lower uniformity of environmental conditions at the study sites. Despite modest broad-sense individual heritability, the estimates of clonal repeatability were rather high. The results from the present study agree with previous findings that the heritability of wood density varies from medium to high and is highest among growth and wood quality traits usually surveyed in tree breeding studies $[6,10,51]$. However, genetic variation was lower for wood density than for other traits. The coefficient of genetic variation $\left(C V_{G}\right)$, that is, the genetic variance standardized to trait mean, is considered to be the most suitable parameter for comparisons of genetic variation and the ability to respond to natural or artificial selection [19]. $C V_{G}$ for wood density was rather low. However, its values were similar to those found in other studies for height growth [5]. In the present study, the $C V_{G}$ for wood density of cumulated rings was rather stable over the 10-year period of the study at almost all sites. Therefore, the age for an efficient early clonal selection would depend to a great extent not only on $C V_{G}$ but also on the time when high repeatability is reached. At three of the four sites studied here, high repeatability estimates were obtained at 5 years of age. Thus, this age could be considered to be appropriate for early clonal tests and selection. However, the optimum age for efficient selection in wood density will also depend upon genetic correlations between juvenile and final wood density.

$C V_{G}$ for dry fiber weight was much higher than it was for wood densities at almost all ages and sites. However, clonal repeatability for dry fiber weight reached its maximum later, at 9 to 10 years of age, than it did for wood density traits. To a great extent, this is due to a late culmination of repeatability of ring width, which is integrated into this composite trait. Thus, high genetic gains in fiber biomass resulting from high genotypic variation and repeatability in dry fiber weight could be expected when clonal selection is made from at least 9 years of age.

A limited number of ramets per clone and clones per hybrid cross, different origins and differences in relatedness strongly influence homogeneity of clonal variances and the level of true genetic variances within each hybrid cross. Therefore, instead of analysing within each hybrid the analysis was carried out on all hybrids pooled. These shortcomings in experimental design, materials, and representation does not allow for a precise estimation of genetic parameters, making far reaching generalizations or for unambiguous reasoning of observed patterns of variation.

Statistically significant $\mathrm{G} \times \mathrm{E}$ interactions corresponding to clone $\times$ site effects were observed for most wood density traits. This trend is in agreement with previous reports on wood density of poplar hybrids [10,51]. Some other studies on poplars $[13,32,39]$ did not find $\mathrm{G} \times \mathrm{E}$ interactions for wood density traits. However, this absence of interaction was probably because of small differences in environmental growth conditions or because too few sites were involved. Shelbourne [43] suggested that problems in testing and selection arise if the interaction variance component reaches $50 \%$ or more than the clone variance component. The clone $\times$ site interaction components for wood density in the present study were of the same magnitude or even exceeded the clone variance components at certain ages. As indicated by not very strong rank correlations (at 3 years of age it ranged from 0.24 to 0.85 and from 0.74 to 0.82 at 10 years of age), rank changes played significant roles in clone $\times$ site interactions. Thus, the clone $\times$ site interaction in wood density traits of hybrid poplars must be considered in tree breeding selection schemes for the region encompassed by the study sites.

\subsection{Changes in genotypic correlations between traits with age}

There has been no study on changes of genetic or genotypic correlations with age conducted on wood density parameters in poplar hybrids. Significant negative genotypic correlations between mean wood density of cumulated rings and ring width were noted at the Saint-Ours and Saint-Anselme sites. These correlations showed a clear tendency to weaken with age from strong to moderate. This trend suggests that at later ages of selection for fast growth, decreases in wood density may be less dramatic. The decrease of correlations with age 
can explain why results from previous studies on the relation between growth rate and wood density in poplar species or poplar hybrids are often controversial. Significant negative genetic or genotypic correlations have been found in some studies $[4,11-13,16,35,44]$ while they were absent in other studies $[8,10,21,29,38,51]$. Another reason for the controversial findings may be variable environmental effects. Such an observation is supported by the results of the present study, indicating that the strength of genotypic correlations between ring width and wood density and the extent of correlations weakening with age differed over sites. Strong genotypic correlations between mean and minimum wood density and weaker correlations with maximum wood density show that wood density is predetermined to a greater degree by minimum wood density than by maximum wood density.

Previous studies $[48,51]$ advocate that dry fiber weight can be used as a complex selection index which combines volume and wood density in a most natural and economically feasible way, allowing the achievement of a high genetic gain in dry biomass production while at the same time minimizing the adverse effect on wood density. However, genotypic correlations between wood density and dry stem fiber weight at some sites were still moderately to strongly negative. Therefore, the use of dry fiber weight as the main selection criterion in breeding for increased dry biomass production in hybrid poplars cannot always prevent losses in wood density. Some additional measures, such as imposing a restriction to limit changes of wood density to zero, should be considered to avoid a decrease of wood density when selection is based on dry fiber weight.

\subsection{Age-to-age genotypic correlations}

Strong age-to-age genotypic correlations were found in this study for most wood properties at 10 years of age and as early as 4 to 6 years, in accordance with reports on generally high age-to-age genetic correlations in coniferous species $[15,20,46]$. Such correlations found in our study were upwardly biased to some extent, due to autocorrelations. The low precision of genetic correlations resulted from large errors of clonal variance and covariance estimates, which were due to the limited number of ramets and clones available for the study. However, they still indicate that the ranking of clones did not change from 4 or 6 to 10 years of age. Thus, the predictive value of wood density at this age is as good as at age 10 . Such an observation suggests that selection of hybrid poplar clones for wood density can be initiated as early as 4 to 6 years of age. Hodge et al. [17] reported that age-to-age correlations for growth traits were low in coniferous species. However, in the present study, these correlations for ring width were of the same strength as for wood density for at least two sites. On the other hand, for the Platon and Windsor sites, it was not possible to estimate these age-to-age correlations, as clonal effects were not significant.

\subsection{Implications of changes in genotypic parameters for tree breeding strategies}

Decreasing age trends in wood density were observed for all poplar hybrids at all sites over the entire time period of the study. This trend indicates that wood is still at a juveniletransitional phase for up to 10 years, which precludes farreaching conclusions on final wood density change as further wood maturation is expected. However, the estimates obtained for cumulated rings for a 10-year period can be considered as rather good predictors of wood density and its related genotypic parameters, in the case of selection of poplar hybrid clones for short rotation plantations. Thus, early estimates can be used for evaluating genetic gain and for choosing an optimal strategy and age of selection.

The variable magnitudes of genotypic parameters observed over test sites and differing trends of changes with age indicate that the genetic background of each trait studied is not the same, and thus, the outcomes of selection are rather different depending on the target characteristic, site and age. The coefficients of genotypic variation for mean wood density of cumulated rings were rather stable from 3 to 10 years of age at almost all sites, with the same values as those found in other studies of tree height, a main selection criterion in tree breeding. Thus, genotypic variation over this period can provide the same opportunities for genetic improvement of wood density as it can for tree height. Moreover, the heritability of wood density was higher than it was for tree height (Pliura et al. submitted) and even increased quite considerably by 5 or 6 years of age. Therefore, genetic gains higher than those expected for height growth can be expected starting from this age. In addition, high genetic gains in fiber biomass could also be obtained, resulting from the large genetic variation seen in dry fiber weight. However, these gains could be obtained starting from 9 to 10 years of age, as clonal repeatability for this complex trait reached its maximum later than it did for wood density.

The present study also shows that the choice of parentage in crosses is of great importance in improving wood density of hybrid poplars, as hybrid variation was of the same or even higher magnitude than clonal variation, and as it showed a tendency to increase from 7 or 9 years of age. However, hybrid selection can be feasible only at productive sites, as the differences in wood density among hybrids were more pronounced for these sites. Hybrid selection could be initiated as early as 4 to 5 years of age, as the trend lines for wood density of cumulated rings of all hybrids became almost parallel at this age, with no further apparent rank changes.

The simultaneous improvement of growth and wood properties of poplar hybrids is considered to be impractical when strong negative relationships exist between wood density and growth $[4,35]$. However, strong negative genotypic correlations between ring width and wood density were found only at two of four study sites. Furthermore, these correlations showed a tendency to weaken with age, suggesting that selection for growth may have less negative effects on wood density with increasing age. 
Strong age-to-age genotypic correlations between wood density at 10 years of age and earlier ages starting from 6 years suggest that selection for wood density may be efficient from this early age, given that tree breeding objectives aim at producing breeding material for intensive plantations with rather short rotation periods. The postponing of selection could give few or no advantages, given that it may lead to a decrease of genetic gain per unit of time.

Acknowledgements: The study was funded by Forintek Canada Corp. and by the Ligniculture Québec Network under the framework of a Valorisation Recherche Québec grant. The authors would like to thank G. Chauret and Q.B. Yu (Forintek Canada Corp.), Pierre Périnet and S. Morin (Québec Ministry of Natural Resources, Fauna and Parks), and P. Gagné (Ligniculture Québec, Univ. Laval branch) for their assistance in collecting samples. Thanks are also due to $\mathrm{N}$. Noel (Univ. Laval and Forintek Canada Corp.) for her assistance with $\mathrm{X}$-ray densitometry.

\section{REFERENCES}

[1] Becker W.A., Manual of quantitative genetics, Academic Enterprises, Pullman, Washington DC, 1984.

[2] Bendtsen B.A., Senft J., Mechanical and anatomical properties in individual growth rings of plantation-grown eastern cottonwood and loblolly pine, Wood Fiber Sci. 18 (1986) 23-38.

[3] Bendtsen B.A., Maeglin R.R., Deneke F., Comparison of mechanical and anatomical properties of eastern cottonwood and Populus hybrid NE-237, Wood Sci. 14 (1981) 1-14.

[4] Beaudoin M., Hernandez R.E., Koubaa A., Poliquin J., Interclonal, intraclonal and within-tree variation in wood density of poplar hybrid clones, Wood Fiber Sci. 24 (1992) 147-153.

[5] Cornelius J., Heritabilities and additive genetic coefficients of variation in forest trees, Can. J. For. Res. 24 (1994) 372-379.

[6] Dadswell H.E., Fielding J.M., Nicholls J.W., Brown A.G., Tree to tree variations and the gross heritability of wood characteristics of Pinus radiata, TAPPI 44 (1961) 174-179.

[7] Danusevicius D., Lindgren D., Efficiency of selection based on phenotype, clone and progeny testing in long-term breeding, Silvae Genet. 51 (2002) 19-26.

[8] DeBell D.S., Singleton R., Harrington C.A., Gartner B.L., Wood density and fiber length in young Populus stems: relation to clone, age, growth rate, and pruning, Wood Fiber Sci. 34 (2002) 529-539.

[9] Falconer D.S., Introduction to quantitative genetics, 3rd ed. Longman, London and New York, 1989.

[10] Farmer R.E. Jr., Variation and inheritance of eastern cotton wood growth and properties under two soil moisture regimes, Silvae Genet. 19 (1970) 5-8.

[11] Farmer R.E. Jr., Genetic variation among open-pollinated progeny of eastern cottonwood, Silvae Genet. 19 (1970) 149-151.

[12] Farmer R.E. Jr., Wilcox J.R., Specific gravity variation in a lower Mississippi valley cottonwood population, TAPPI 49 (1966) $210-211$

[13] Farmer R.E. Jr., Wilcox J.R., Preliminary testing of eastern cottonwood clones, Theor. Appl. Genet. 38 (1968) 197-201.

[14] Gonzalez J.S., Richards J., Early selection for wood density in young coastal Douglas-fir trees, Can. J. For. Res. 18 (1988) $1182-1158$.

[15] Hanrup B., Ekberg I., Age-age correlations for tracheid length and wood density in Pinus sylvestris, Can. J. For. Res. 28 (1998) $1373-1379$
[16] Hernandez R.E., Koubaa A, Beaudoin M., Fortin Y., Selected mechanical properties of fast-growing poplar hybrid clones, Wood Fiber Sci. 30 (1998) 138-147.

[17] Hodge G.R., White T., Powell G., Genetics of wood density characteristics in slash pine, in: Coop. For. Gen. Res. Prog. 34th Prog. Ep. Univ. Florida Gainesville, FL, 1992, pp. 12-20.

[18] Holt D.H., Murphey W.K., Properties of hybrid poplar juvenile wood affected by silvicultural treatments, Wood Sci. 10 (1978) 198-203.

[19] Houle D., Comparing evolvability and variability of quantitative traits, Genetics 130 (1992) 195-204.

[20] Hylen G., Age trends in genetic parameters of wood density in young Norway spruce, Can. J. For. Res. 29 (1999) 135-143.

[21] Ilstedt B., Gullberg U., Genetic variation in a 26-year old hybrid aspen trial in southern Sweden, Scand. J. For. Res. 8 (1993) 185-192.

[22] Ivkovich M., Genetic variation of wood properties in balsam poplar (Populus balsamifera L.), Silvae Genet. 45 (1996) 119-124.

[23] Ivkovich M., Namkong G., Koshy M., Genetic variation in wood properties of interior spruce. I. Growth, latewood percentage, and wood density, Can. J. For. Res. (2002) 2116-2117.

[24] Johnson L.P., Studies on the relation of growth rate to wood quality in Populus hybrids. Can. J. Res. 20 (1942) 28-40.

[25] Koga S., Zhang S.Y., Relationships between wood density and annual growth rate components in balsam fir (Abies balsamea), Wood Fiber Sci. 34 (2002) 146-157.

[26] Koubaa A., Hernandez R.E., Beaudoin M., Shrinkage of fastgrowing hybrid poplar clones, For. Prod. J. 48 (1998) 82-87.

[27] Larson P.R., Silvicultural control of the characteristics of wood used for furnish, in: Proc. 4th TAPPI For. Biol. Conf., New York, 1967, pp. $143-150$

[28] Louzada J.L.P.C., Fonseca F.M.A., The heritability of wood density components in Pinus pinaster Ait., and the implications for tree breeding, Ann. For. Sci. 59 (2002) 867-873.

[29] Matyas C., Peszlen I., Effect of age on selected wood quality traits on poplar clones, Silvae Genet. 46 (1997) 64-72.

[30] Megraw R.A., Wood quality factors in loblolly pine, TAPPI Press Atlanta, Georgia, 1985, 89 p.

[31] Mutibarić J., Comparative qualitative relationships of wood properties of Euramerican poplars, Silvae Genet. 20 (1971) 199-204.

[32] Nepveu G., Barneoud C., Polge H., Aubert M., Variabilité clonale des contraintes de croissance et de quelques autres propriétés du bois danc le genre Populus, in: Fiabilité de l'appréciation de la qualité du bois à l'aide de carottes de sondage, Annales de Recherchers Sylvicoles, AFOCEL, France, 1986, pp. 337-357.

[33] Nepveu G., Keller R., Tessier du Cross E., Sélection juvénile pour la qualité du bois chez certains peupliers noirs, Ann. Sci. For. 35 (1978) 69-92.

[34] Okkonen E.A., Wahlgren H.E., Maeglin R.R., Relationships of specific gravity to tree height in commercially important species, For. Prod. J. 22 (1972) 37-41.

[35] Olson J.R., Jourdain C.R., Rousseau R.J., Selection for cellulose content, specific gravity and volume in young Populus deltoides clones, Can. J. For. Res. 15 (1985) 393-396.

[36] Phelps J.E., Isebrands J.G., Jowett D., Raw material quality of shortterm, intensively cultured Populus clones. I. A comparison of stem and branch properties at three spacing, IAWA Bull. n.s. 3 (1982) 193-200.

[37] Pliura A., Yu Q., Zhang S.Y., MacKay J., Périnet P., Bousquet J., Variation in wood density and shrinkage and their relationship to growth of selected young poplar hybrid crosses, For. Sci. 51 (2005) 472-482.

[38] Posey C.E., Bridgewater F.E., Buxton J.A., Natural variation in specific gravity, fiber length, and growth rate of eastern cottonwood in the southern Great Plains, TAPPI 52 (1969) 1508-1511. 
[39] Randall W.K., Cooper D.T., Predicted genotypic gains from cottonwood clonal tests, Silvae Genet. 22 (1973) 165-167.

[40] Richardson C.J, Koerper G.J., The influence of edaphic characteristics and clonal variation on quantity and quality of wood production in Populus grandidentata in the Great Lakes region of the USA, Mitteil Forstl. Bundes-Versuchsanstalt Wien 142 (1981) 271-292.

[41] Riemenschneider D.E., Berguson W.E., Dickmann D.I., Hall R.B., Isebrands J.G., Mohn C.A., Stanosz G.C., Tuskan G.A. Poplar breeding and testing strategies in the north-central USA: Demonstration of potential yield and consideration of future research needs, For. Chron. 77 (2001) 245-253.

[42] SAS Institute Inc., SAS/STAT ${ }^{\circledR}$ User's guide, Vers. 8, SAS Institute Inc., Cary, NC, USA, 1999.

[43] Shelbourne C.J.A., Genotype-environment interaction: its study and its implications in forest tree improvement, in: Proc. of Joint Symposia for the Advancement of Forest Tree Breeding of the Genetics Subject Group, IUFRO, and Section 5, Forest Trees, SABRO, Gov. Forest Exp. Station of Japan, Tokyo, 1972, pp. B1 I1-I28.

[44] Stener L.-G., Analys av fiberegeneskaper för kloner av hybridasp, Arbetsrapport nr 387. SkogForsk, Uppsala, 1998 (in Swedish).

[45] Swiger L.A., Harvey W.R., Everson D.O., Gregory K.E., The variance of intra-class correlation involving groups with one observation, Biometrics 20 (1964) 818-826.
[46] Vargas-Hernandez J., Adams W.T., Genetic variation of wood density components in young coastal Douglas-fir: implications for tree breeding, Can. J. For. Res. 21 (1991) 1801-1807.

[47] Yu Q., Pulkkinen P., Rautio M., Haapanen M., Alen R., Stener L.G., Beuker E., Tigerstedt P.M.A., Genetic control of wood physiochemical properties, growth and phenology in hybrid aspen clones, Can. J. For. Res. 31 (2001) 1348-1356.

[48] Zhang S.Y., Morgenstern E.K., Genetic variation and inheritance of wood density in black spruce (Picea mariana) families and its relationship with growth: implications for tree breeding, Wood Sci. Technol. 30 (1995) 63-75.

[49] Zhang S.Y., Zhong Y., Effect of growth rate on specific gravity of East-Liaoning oak (Quercues liaotungensis) wood, Can. J. For. Res. 21 (1991) 255-260

[50] Zhang S.Y., Nepveu G., Eyono Owoundi R., Intratree and intertree variation in selected wood quality characteristics of European oak (Quercus petraea and Quercus robur), Can. J. For. Res. 24 (1994) $1818-1823$.

[51] Zhang S.Y., Yu Q., Chauret G., Koubaa A., Selection for both growth and wood properties in hybrid poplar clones, For. Sci. 49 (2003) 901-908.

[52] Zobel B.J., van Buijtenen J.P., Wood variation, Springer-Verlag Berlin Heidelberg, Germany, 1989

[53] Zobel B.J., Jett J.B., Genetics of wood production, Springer-Verlag, Berlin Heidelberg, Germany, 1995 